\title{
Courtroom Questioning Adapted to Legal Procedures
}

\author{
Hu Haijuan ${ }^{1}$ \\ ${ }^{1}$ College of Continuing Education, Guangdong University of Foreign Studies, Guangzhou, China \\ Correspondence: Hu Haijuan, College of Continuing Education, Guangdong University of Foreign Studies, \\ Guangzhou, China.
}

Received: October 5, 2018 Accepted: December 1, 2018 Online Published: December 6, 2018

doi: 10.5539/elt.v12n1p7

URL: https://doi.org/10.5539/elt.v12n1p7

\begin{abstract}
This paper, taking linguistic theory of adaptation as its theoretical foundation, examines how courtroom questioning on the part of the judge is adapted to various contextual factors in legal setting. To account for the judge's adaptation to the legal procedures in courtroom questioning, three types of questions are found as specific choices at different stages of courtroom trial. By choosing key-word questions, confirmation questions and consultative questions in accordance with the different legal procedures, the judge can decide a case confidently, therefore the institutional goal of solemnity, impartiality and effectiveness are achieved satisfactorily. This paper provides a new understanding of courtroom questioning in Chinese context, which will be a contribution to the general research on forensic linguistics and a pragmatic approach to the rhetoric of questioning in general.
\end{abstract}

Keywords: legal procedures, key-word questions, confirmation questions, consultative questions, institutional goal

\section{Introduction}

This paper focuses on examining courtroom questioning which is understood as an adaptive choice making process. The theoretical framework for the present research is developed from Verschuren's $(1987,1998,1999)$ Theory of Linguistic Adaptation. Following this theory on language use, we argue that courtroom questioning is a dynamic process of realizing the questioners' communicative goals. To support this argument, we will address two questions in this thesis: (1) How is linguistic adaptation realized in courtroom questioning? (2) What functions are realized in the dynamic process of adaptation?

The selection of this research topic is based on the following considerations: First, the use of courtroom questions is of genuine importance. Questions and answers permeate the whole process of courtroom interaction, and guilt is determined and judgments formulated largely on the basis of the outcome of question-answer sequences, so both the questioner and the respondent always choose their language strategically according to the constantly changing context. Nowhere else are the strategic uses of language more evident than in the courtroom (Drew, 1990).

Another reason that motivates the present study on courtroom questioning is the fact that most previous studies on courtroom interaction are based on the Anglo-Saxon jurisdiction, and relevant studies in Chinese context is regretfully few. Until now only several books were published in this field: A General Introduction to Forensic Linguistics (Du \& Zhang, 2002), Studying Legal Language (Wang, 1999), Chinese Legal Language Across the Century (Pan, 1997), Forensic Linguistics (Sun \& Zhou, 1997), etc. Articles about legal language can be found in some journals, but most of them took the grammatical or rhetorical approach, and little work was done about spoken data, especially courtroom interaction. So most data used in this research come from our own recording and transcription of Chinese courtroom trials where similar procedures are practiced as in continental Europe.

The third consideration is purely academic. Previous studies on courtroom interaction have been approached from different perspectives in western countries, but these studies focus mostly on the classification and description of courtroom questions and their stylistic functions or the social constraints on the use of questions, ignoring the fact that what people say and how they say it are generally affected by many other contextual correlates with which they interact. Context, according to Verschueren $(1987,1995,1998,1999)$ and many other pragmatically-oriented scholars (e.g. Leech, 1983; Sperber \& Wilson, 1995), is now believed to be a dynamic construct rather than a static one. It not only functions to shape the speakers' utterances but, in the interactive 
process, is modified and shaped as the result of the communicators' language use (Drew, 1992; Sperber \& Wilson, 1995; Verschueren, 1995, 1998, 1999). Context for these pragmaticians does not only denote the immediate linguistic context; it, in fact, refers to all factors that influence the language users' linguistic choice-making process. Therefore an approach incorporating all these factors is both necessary and essential.

The approach we have decided on for this study, after a careful review of the previous studies and the theories available, is the Theory of Linguistic Adaptation as proposed and elaborated by Verchueren $(1995,1998,1999)$ because it includes the physical, socio-cultural and cognitive contexts as well as the linguistic one. The objectives of this study are: (1) to describe the strategies adopted by the questioners in courtroom trial, and (2) to examine the complexity, functionality and dynamics of the strategies in courtroom questioning. A welcomed result of this analysis may be its use in the adjudication of actual legal cases according to the categories and findings in this paper. Thus, this study will be a contribution to the general research on forensic linguistics and a pragmatic approach to the rhetoric of questioning in general.

This paper is made up of five sections. The first section covers research motivations, research objectives, literature review and the overview of the paper. Section two provides a brief introduction to linguistic theory of adaptation, trying to present a theoretical framework for the paper. Section three introduces data collection and methodology, which is followed in section four by a detailed analysis of the data. The final section presents conclusions, pointing out the limitations of the present study and making suggestions for future research.

\section{Conceptual Model for the Adaptation of Courtroom Questioning}

\subsection{Adaptation Theory}

Verschueren (1999: 58) claims that language use can be defined as the continuous making of linguistic choices, consciously or unconsciously, for language-internal and/or language external reasons, at any level of linguistic form. The idea that using language is a continuous making of linguistic choices is proposed on the basis that language is characterized by variability, negotiability and adaptability. Variability is the property of language which defines the range of possibilities from which choices can be made (Verschueren, 1999: 59). Negotiability is the property of language responsible for the fact that choices are not made mechanically or according to strict rules or fixed form-function relationships, but rather on the basis of highly flexible principles and strategies (ibid: 59). Adaptability is the property of language which enables human beings to make negotiable linguistic choices from a variable range of possibilities in such a way as to approach points of satisfaction for communicative needs (ibid: 61).

Linguistic adaptation can be examined from four inter-related angles for a better pragmatic description and explanation, including contextual correlates of adaptation, structural objects of adaptation, dynamics of adaptation, and the salience of the adaptation process. These four angles are in perfect agreement with the linguistic, social, cultural and cognitive elements involved in the dynamic process of language using. According to Verschueren (1999) contextual correlates of adaptation include all the ingredients of the communicative context with which linguistic choices have to be interadaptable: language users (utterer and interpreter), mental world (such as personality, emotions, beliefs, desires or wishes, motivations or intentions etc. of language users), social world (such as social settings, institutions, culture, etc.) and physical world (such as time, space, bodily postures, physical appearance, physical conditions, biological property, etc.). The contextual correlates of adaptation could be sketched as Figure 1 (Verschueren, 1999).

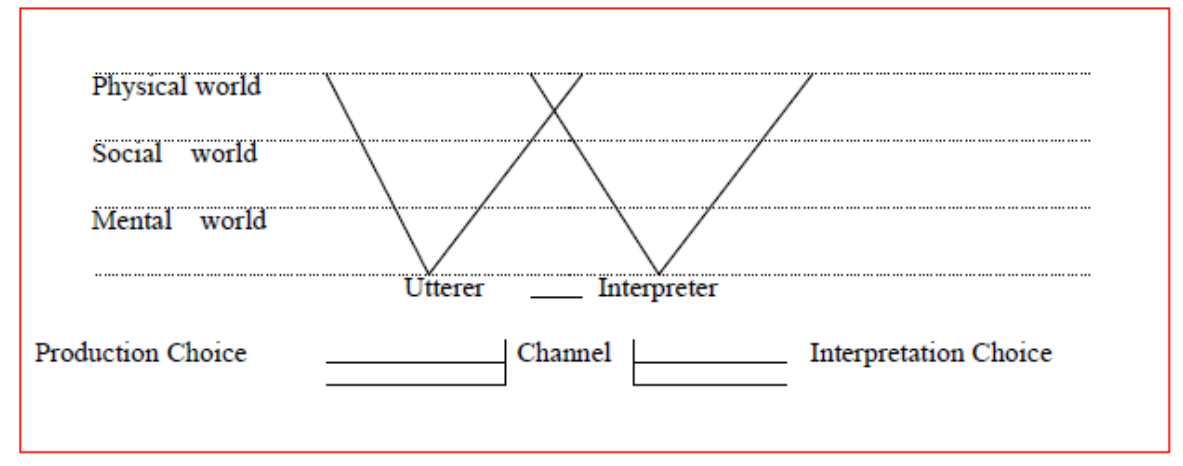

(Linguistic Context)

Figure 1. Contextual correlates of adaptation 


\subsection{Conceptual Framework in Terms of the Factors Influencing the Choice Making Process Involved in Courtroom Questioning}

One of the the contextual correlates to which courtroom questioning adapts is the legal procedure. Legal procedure in this study refers to the order or steps that a courtroom trial should strictly follow in order to achieve the institutional goal of impartiality and effectiveness. As a common practice, the case will be tried in the courtroom after investigation and prosecution. Courtroom trial is the decisive phase of any legal action. By hearing and examining evidences from both sides, the judge and often the collegiate bench will decide if the person accused of a crime is innocent or guilty. In China, the courtroom trial shall strictly follow the following procedures: (a) opening the court or declare the court in session, (b) courtroom investigation, (c) courtroom argument, (d) the defendant's final statement, and (e) deliberation and sentence. Courtroom questioning as the realization of the questioners' adaptation to the legal procedures stands for the dynamic choice-making process subject to the procedural requirements. In courtroom questioning, the judge should strictly base their questions on the procedures, i.e., at different stage of courtroom trial, different questions should be asked to ensure the impartiality of the trial.

The conceptual framework derived from the above discussion is an adaptation model designed to explain courtroom questioning as a dynamic choice-making process. It is necessarily constructed from the speaker's point of view, intending to disclose and explain the questioner's choice of questions rather than the respondent's interpreting and understanding of questions. This framework is intended to offer a better answer to the question: what questioners do when interrogating the defendant or witness? And the framework can be tentatively formulated as the following figure.

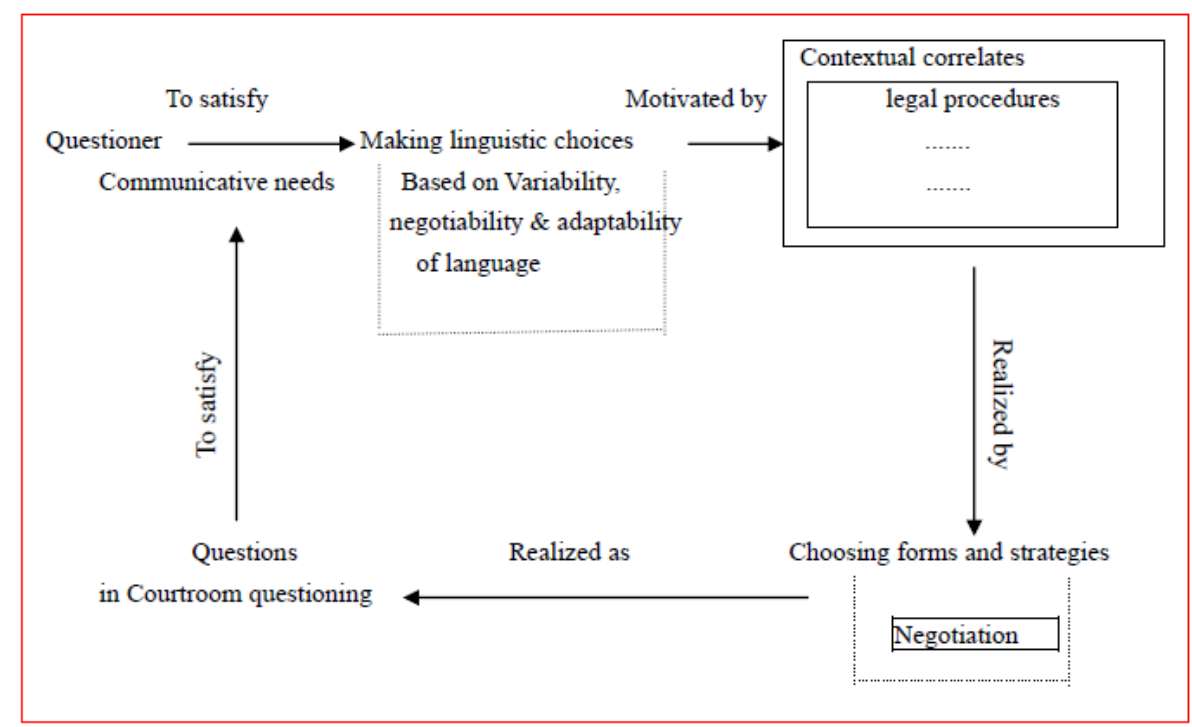

Figure 2. An adaptation model explaining courtroom questioning

This framework treats courtroom questioning as a process of linguistic choice, which is the fundamental and intrinsic property of language use. All instances of language use are basically a process of choice making. Verschueren (1987) argues that using language in general consists of constant linguistic choice making, consciously or unconsciously, for linguistic or extra-linguistic reasons. And the choices are situated at every possible level of linguistic structures. It is based on the variability, negotiability and adaptability of language that linguistic choices can be made to satisfy different communicative needs.

It is human beings' nature to adapt themselves to the environment for survival. They make adaptation in interaction to approximate or effectuate their communicative goals that are specific for each communicative context (i.e., the contextual correlates including the social-legal and mental world as sketched in the above figure), and the success of adaptation will benefit human beings' survival in the long run. In the dynamic process of making adaptation, language users have to abide by various communicative principles and strategies for the negotiation of particular meanings of each question, and these principles and strategies to a greater degree contribute to the negotiation and adaptation. After the successful consummation of adaptation and negotiation, 
there come the questioners' final verbal products - questions in courtroom questioning; with the particular question in specific communicative context, the questioner can satisfy his own communicative needs in the adaptation process.

\section{Data Collection and Methodology}

The study is a qualitative one, so the process of study proceeds from observing and collecting naturally occurring data in courtroom trial to their classification and description. For the purpose of this study, Chinese data are analyzed in courtroom questioning. All Chinese data are transcripts of several trials in criminal courts, randomly chosen from the 2000-2001 period. Incomplete utterances, obscure expressions, hesitations are generally filtered out; in addition, some potential over- or under-interpretations can not be excluded. Consequently, the following account does not claim to be exhaustive.

\section{Data Analysis}

Courtroom trial is such a complicated process involving many participants with different purposes; only when all the procedures are strictly adapted to, can the solemnity, impartiality and effectiveness of the trial process be ensured. In order to adapt to the specific legal procedures, the judge has to choose different questioning patterns and strategies to achieve his communicative purpose in different contexts. By analyzing the data collected for the present study, we find three types of typical questions in courtroom trial as a result of adaptation to the legal procedures, namely (1) key-word question, (2) confirmation question, and (3) consultative question.

This section focuses on answering the following questions: How is the courtroom questioning adapted to the legal procedures? What functions are realized in the dynamic process of adaptation to the legal procedures? Data analyzed in this section are taken from the transcription of a criminal trial (Note 1) about misappropriating public funds and tax evasion at Beilunqu People's Court of Ningbo City on April 16th, 2001. As all questions in this part are in a relatively formulaic pattern, a broad transcription (Note 2) is adopted.

\subsection{Key Word Questions}

Key word questions, as the name suggests, refer to questions focusing on the most important information with elliptical forms. We can find an abundance of key word questions from the following extract:

(1).

Q1:被告人姓名? formal address term + Q-what (name)

Q1: (What is) the name of the defendant?

A:----。

Q2:出生年月日? Q-when (birthday)

Q2: (When was the defendant born) birthday?

A:----。

Q3:籍贯? Q-where (native place)

Q3: (Where is the defendant's ) native place?

A:----。

Q4:住址? Q-where (address)

Q4: (Where does the defendant live) address?

A:----。

Q5:职业? Q-what (occupation)

Q5: (What is the defendant's) occupation?

A:----。

Q6:文化程度? Q-what (education background)

Q6: (What is the defendant's) education background?

A:----。

Before the actual trial begins, the identity of the defendant must be verified for fear that any innocent person would be tried wrongly. It is this consideration that motivates the presiding judge to adapt the trial to questioning the defendant about his personal information. It's a convention that all criminal trials begin with such key word 
questions as in Extract 1, which only consist of key words instead of using everyday complete sentences such as“请问您贵姓? (May I know your name?)” with a polite second-person pronoun “您” and other polite words “请 (please)” “贵(respected)”, which can greatly reduce the solemn and impartial atmosphere of the courtroom trial.

Q1 is asked with a very formal address term “被告人”. Adelsward et al. (1988) describe forms of address as well-known devices for regulating social distance and expressing power and solidarity, affiliation or non-affiliation. In court, judges and lawyers may employ different addresses and naming strategies to express affiliation or non-affiliation consciously or unconsciously. Another strategy often adopted in formal situations is to avoid pronouns. In Extract 1, the strategy of using an impersonal construction (no address form at all) is very prominent. Lawyers and judges, in most cases, address the defendant impersonally. Such technical legalese as “被告人” and the impersonal strategy employed in the questioning can better serve the purpose of impartiality and non-affiliation of the judge as the law enforcement representative.

In order to make sure that the person with such a name is really the one who is involved in the case, other information about birthday, native place and address is further inquired in the following three key word questions “出生年月日 (birthday)?”“籍贯 (native place)?” “住址 (address)?”. Questions 5-6 are about the defendant’s social and educational backgrounds with which the questioner can carefully formulate his or her question accordingly to ensure comprehension.

All the six key word questions are short and in a relatively fixed verbal routine, which can satisfy the procedural requirement of brevity and relevance. As a result, the efficiency of courtroom trial can be enhanced and meanwhile the formal, solemn and impartial atmosphere of courtroom trial can be created. This specific questioning pattern in Extract 1 is the concrete realization of the judge's adaptation to the legal procedures concerning identity verification which can ensure that the person in court really is the one whose name is associated with the charge.

\subsection{Confirmation Questions}

Confirmation questions are defined as questions intended to make sure that the questionees fully understand what is said and what is implied so that they can perform their obligations and exercise their legal rights accordingly. In courtroom trial, mutual knowledge is what the presiding judge strives for in order to avoid misunderstanding and therefore ensure the fairness of the judgment. As Sperber and Wilson (1995:19) put it:

“...it is true that people sometimes go to great lengths to avoid misunderstanding... In legal proceedings, for instance, there really is a serious attempt to establish mutual knowledge among all the parties concerned..."

To this end, confirmation questions can obviously avoid misunderstanding while enhancing the mutual knowledge. This kind of questions in courtroom trial is usually formed in such a special way as: statement or precursor + comprehension check (e.g. “你听清楚了吗 Are you clear?)”, which can be illustrated in the following examples:

Q1：根据中华人民共和国刑事诉讼法第一百五十二条的规定，本法庭依法适用普通程序公开审理，宁波 市北仑区人民检察院提起公诉的被告人陈均夫挪用资金、偷税一案。本合议庭由审判员...组成合议 庭...Statement (enumerate participant roles)

Q1: According to Article 152 of the Criminal Procedure Law of the People's Republic of China, this court will do a public hearing under formal procedure on the defendant Chen Junfu's embezzlement and tax evasion trial, which is prosecuted by the People's Procuratorate of Beilun District, Ningbo City. The collegial panel is composed of ......

根据最高人民法院《关于审理刑事案件程序的具体规定》第一百零三条之规定，当事人在法庭上享有如 下权利:(elaborate on the legal rights)

In accordance with Article 103 of Detailed Provisions on the Court Trial Procedures for Criminal Cases issued by the Supreme People's Court, the parties have the following rights in the court.

被告人, 刚才本庭告知的权利听清了没有? Q-y/n (precursor + comprehension check)

Defendant, are you clear with the rights?

Q2:根据《中华人民共和国刑事诉讼法》第 48 条、第 47 条的规定, “凡是知道案件情况的人, 都有作证 的义务。“法庭查明证人有意作伪证或者隐匿罪证时, 应当依法处理”。这是证人的义务, 你听清楚了 
吗? Statement (obligations ) + Q-y/n (comprehension check)

Q2: According to Article 48 and Article 47 of Criminal Procedure Law of the People's Republic of China, "All those who have information about a case shall have the obligation to testify", and "If a court discovers through investigation that a witness has intentionally given false testimony or concealed criminal evidence, he shall be handled in accordance with law." This is the obligation of the witness. Are you clear?

Q3:如果不服本判决, 可在接到判决书三日起十五日内向本院递交上诉状, 或者直接向宁波市中级人民法 院上诉, 并按对方当事人的人数提出副本。你听清楚了吗? Statement + Q-y/n (comprehension check of the legal rights)

Q3: If the defendant refuses to accept the present judgment as final and binding, he may appeal to the Intermediate People's Court of Ningbo directly or to this court within 15 days commencing on the third day following the day of receipt of this written judgment. Duplicates of the original petition for appeal shall be submitted to the parties involved in the case. Are you clear?

In courtroom trial, it is a common pattern for the judge to elaborate on the rights or obligations in detail; a comprehension check follows to ensure the full understanding of the statement. "The detailed elaboration on participant roles, legal rights and obligations together with the comprehension check" (Phillip 1998) can ensure the mutual knowledge between the judge and the defendant.

Q1 consists of two statements and a Y/N question as a comprehension check. The first statement enumerates participant roles in a formal and set pattern: “根据.... 本法庭...公开审理...本合议庭由...组成; 书记员...检 察员...辩护人...”. Most importantly, the presiding judge makes it clear in the second statement that the defendant is entitled to enjoy litigious rights to defend himself (if he can't afford a lawyer, the court will appoint one for him) and apply for the withdrawal of judges, jurors, secretary, expert witness or interpreter. The courtroom rule requires that the judge "address the defendant personally in open court" and determine that the defendant understands all that is required by law for the procedure to be valid. So after elaborating what the rights are, “被告人，刚才本庭告知的权利听清了没有? ”is employed to check the defendant's understanding of legal rights. If there is anything unclear, the defendant is entitled to ask the judge for further clarification or explanation. This kind of comprehension check is necessary to ensure that the defendant fully enjoys the legal rights.

In the first part of Q2, the judge states the obligations of the witness according to the law, which makes the witness realize the seriousness of testifying and the consequence of committing perjury. Immediately after the statement , a comprehension check “你听清楚了吗? (Are you clear?)” follows as a deterrent for the witness to provide fabricated or distorted testimony. A positive answer from the witness implies that he has committed himself to presenting the true story; otherwise he would take on the consequence of committing perjury.

Q3 is advanced at the end of the trial. After the sentence is announced, the presiding judge informs the defendant that if he is not satisfied with the judgment he is entitled to appeal to a higher court in a certain way and at a certain period, which fully embodies the impartiality and justice of law and ensures the defendant's legal rights. This procedure can effectively prevent innocent people from being treated wrongly or unjustly.

(2b).

Q4: 被告人, 陈均夫, 刚才公诉人宣读的这份证据听清了吗？ precursor(address) $+\mathrm{Q}-\mathrm{y} / \mathrm{n}$

Q4: Defendant Chen Junfu, are you clear with the testimony presented by the Prosecutor?

Q5: 就这个购车证明, 被告人听清了吗? precursor(focusing) $+\mathrm{Q}-\mathrm{y} / \mathrm{n}$

Q5: Defendant, are you clear with the certificate of car purchase?

Q6: 被告人陈均夫, 证人岳某的证言, 你听清楚了吗? 有没有意见? precursor (address) $+\mathrm{Q}-\mathrm{y} / \mathrm{n}+\mathrm{Q}-\mathrm{y} / \mathrm{n}$

Q6: Defendant Chen Junfu, are you clear with the testimony of Yue? Do you have any opinion?

After the testimony or evidence is presented or advanced, the presiding judge checks the defendant if he has fully understood everything presented with the comprehension check “你听清楚了吗 (Are you clear)?”. This is a necessary step for the whole procedure to be valid, because the testimony or evidence presented is closely related to the detail of the case story and it is the most important basis for the judge or collegiate bench to formulate the judgment. Only when the defendant is clear about the prosecution evidence, can he fully exercise his right to present objection or, if possible, reshape the unfavorable evidence for his own benefit.

By asking confirmation questions in such a formulaic pattern, the judge successfully adapts the questioning to the procedural task of mutual knowledge; in other words, confirmation questions can make the parties concerned 
beware of their rights and obligations. In short, this type of questioning can guarantee a fair and just trial.

\subsection{Consultative Questions}

Consultative questions in the present study are taken as a means of seeking possible responses from the questionees, with which questioners can refrain themselves from being subjective and biased. In the light of the spirit of humanity of law, criminals, like other human beings, are entitled to some basic human rights, though they are different in the sense that they must confess what they have committed. In courtroom trial, consultative questions of this type are most often presented with the “是否”, “有无”, “有...没有”, “...吗” patterns.

(3a).

Q1：你以前是否受到过法律处分? Q-y/n (previous involvement in legal action)

Q1: Have you ever been involved in any legal action?

Q2:是否要申请回避? Q-y/n (apply for the withdrawal)

Q2: Do you apply for the withdrawal?

Q3:公诉人是否还有新的---证据向法庭提供? Q (正反)

Q3: Prosecutor, do you have any new evidence?

Q4: 公诉人是否有证明被告人无罪或者罪轻的证明向法庭提供? Q（正反）

Q4: Prosecutor, do you have any evidence to prove the innocence or the venial punishment of the defendant?

Q5: 辩护人是否有证据向法庭提供? 被告人有证据向法庭提供吗? Q1（正反）+Q2-y/n（Q1 to two addressees, Q2 to one of them)

Q5: Defender, do you have any evidence to present to the court? Defendant, do you have any evidence to present to the court?

Q6: 是否申请通知新的证人到庭调取新的物证申请重新鉴定或者勘验? Q（正反）

Q6: Do you apply for the presence of new witness, new evidence or the re-authentication of the evidence?

Q7: 公诉人是否还有新的公诉意见? Q (正反)

Q7: Prosecutor, do you have any other opinions?

Q8: 辩护人是否还有川（什么？）辩护意见吗？Q (正反)

Q8: Defender, do you have any other opinions?

If the defendant is a hardened criminal, an aggravated punishment would be considered in the final conviction. In this sense, Q1 about record of previous involvement in legal action is a necessary adaptation for the judge or collegiate bench to determine the penalty. Q2 “是否要申请回避? ” asks the defendant if he applies for the withdrawal of any participant who may cause an unfair judgment of the case. Any judges, jurors, secretary, expert witness and interpreter who are closely related to the final judgment of the case will be excluded from the trial process.

The presiding judge, "as a neutral assessor of the prosecution and defense evidence and as regulator of what is allowable in terms of legal process" (Adelsward 1988), holds an impartial and unbiased position in the trial. The consultative question with “是否(yes or no)" makes it possible for the questionees to provide an objective answer without being influenced by any presupposition implied in the question, that is, they can freely choose whether to take the floor (to speak or address the audience) or give it up.

Q3 and Q4 are intended to give the floor to the prosecutor to present further evidence aiming at fully supporting his prosecution. Q5 and Q6 are adapted to provide the chance for the defendant or his lawyer to exercise his legal rights such as advancing favorable evidence, applying for summoning new witness to the court or investigating new evidence. In Q7 and Q8, the presiding judge asks if the prosecutor and the defending lawyer have any complementary statements before winding up the courtroom examination, which can ensure the objectivity and impartiality of the final judgment.

(3b).

Q9: 辩护人对被告人有无发问? precursor(address) $+\mathrm{Q}-\mathrm{y} / \mathrm{n}$

Q9: Defender, do you have any question for the defendant?

Q10：对此有无异议？Q-y/n 
Q10: Do you have any objection?

Q11:辩护人\|有无异议? precursor(address) $+\mathrm{Q}-\mathrm{y} / \mathrm{n}$

Q11: Defender, any objection?

Q12: 公诉人, 你对证人岳传杰还有什么要问的没有? Q-y/n

Q12: Prosecutor, do you have any question for the witness Yue Chuanjie?

Q13:被害人王海生，你有什么要问证人的没有? Q-y/n

Q13: Victim Wang Haisheng, do you have any question for the witness?

Q14:被告人，还有辩护意见没有? precursor(address)+Q-y/n

Q14: Defendant, do you have any defense opinion?

Q15:辩护人你有什么要问的没有? precursor(address)+Q-y/n

Q15: Defender, do you have any question?

Q16:被告人陈均夫你有没有什么要问的? precursor(address)+Q-y/n

Q16: Defendant Chen Junfu, do you have any question?

Q9-16 are all clothed in “有无” and “有...没有” patterns, which are another type of consultative questions dealt with in the present study. In Mandarin Chinese, “有无” and “有...没有” play the same role as “是否” in such questions. The questionee can either choose a positive or negative answer out of his own will. As a result the legal procedure can be carried out justly.

After the party concerned presents the relevant testimony, the presiding judge asks the above consultative questions to make sure if the parties concerned (“有无异议”) have any objection. The procedure of cross-examination can facilitate a deeper and more objective evaluation of the evidence. When there is not any disagreement, the testimony can be finally confirmed. The whole process fully embodies the justice and fairness of the trial system.

Every participant follows a strict procedural order, and nobody shall speak when not asked or permitted. Failure to comply with the rules of the court will lead to reprimand, a fine or even a jail sentence for contempt of court. Atkinson and Drew (1979) wisely infer that the formality of the court situation is presumably a product of the desire to avoid everyday communication problems by regulating the communicative process as much as possible. In everyday conversation, both parties can introduce a topic or volunteer information, but in legal situations, only when the above consultative questions are asked, can the parties concerned be permitted to take the floor. This kind of institutional requirements can avoid the kind of disorder or confusion in everyday conversation because courtroom questioning is a process full of conflict, and every utterance is closely related to the personal interest of the parties concerned. By adapting courtroom questioning to the procedure, unnecessary arguments, quarrels or even personal attacks that usually occur in adversary system can be avoided, so both the solemnity and efficiency of law can be ensured.

(3c).

\section{Q17:被告人陈均夫, 刚才公诉人宣读的起诉书与你收到的起诉书副本内容一样吗? Q-y/n}

Q17: Defendant Chen Junfu, is the indictment presented by the prosecutor the same as the copy of indictment you received?

Q18:你对于本庭今天审理陈均夫挪用资金、偷税一案所涉及的事实了解吗？ Q-y/n (qualification as witness)

Q18: Do you know the facts involved in the case of Chen Junfu's embezzlement and tax evasion heard before the court today?

As a special variety of the consultative question, Q17 and Q18 are presented in a “...吗” pattern. Q17 appears after the prosecutor reads out the complaint. This part of the procedure is highly routinized. The complaint read out in the court should be in strict conformity with the copy received by the defendant before the court is in session. Any substantial inconsistency will ruin the procedure because it can prevent the defendant from fully exercising his right to defend himself against the accusation presented in the complaint. Q18 is a procedural question functioning as a check of the respondent qualification as a witness, i.e. when he is clear about the facts involved in the case, his qualification as a witness can be confirmed, and thus the subsequent questioning becomes possible.

In addition to the above three types of questions, another type which merits our attention is "specific question". 
Specific questions are generally designed to seek detailed information concerning such aspects of events as time, place, etc. One extract in point will be given as follows:

(4).

\section{Q1:你因本案何时被刑事拘留，何时被依法逮捕？Q-when (time of arrest)}

Q1: When were you detained in connection with this case? And when were you arrested?

Q2:宁波市北仑区人民检察院起诉书副本收到没有? 何时收到? Q-y/n + Q-when (the receipt of the complaint)

Q2: Did you receive the copy of indictment of People's Procuratorate of Beilun District, Ning Bo City? When did you receive it?

In the above extract, one can easily find three $w h$-questions uttered to elicit the detailed information that must be transmitted before the legal procedures can be carried out. By asking Q1 the presiding judge inquires the defendant about the time of detention and arrest. If the defendant is held in custody beyond the specified term, he is entitled to claim his right of personal freedom in accordance with the law. ("A term of criminal detention shall be not less than one month but not more than 6 months" Chapter three, section 3, article 42, Criminal Law of the People's Republic of China). Therefore, after the defendant is detained, the case should be investigated and prosecuted within a certain period. Q2 is accommodated to checking if the law enforcement agency has performed their duty efficiently and if the personal right of the defendant is violated. Only when the complaint reaches the defendant in due time, can he fully prepare for the trial accordingly. Adjusted to this procedural requirement, a yes/no question and a $w h$-question are advanced about the receipt of the complaint.

\section{Conclusion}

The above analysis leads us to the conclusion that courtroom procedures at different stages motivate questioner's linguistic choices, and all the formulaic utterances as specific linguistic choices at different stages of courtroom trial are the result of questioner's long-term adaptation to the legal procedures in the special institutional context of courtroom questioning. By choosing key-word questions, confirmation questions and consultative questions in accordance with the different legal procedures, the judge can decide a case confidently without wondering whether they have sentenced an innocent person to jail or let a criminal go free. As a result, the rights and interests of the parties concerned can be upheld and the institutional goal of solemnity, impartiality and effectiveness will be achieved satisfactorily.

A weak point of the present study is the limited amount and sources of data examined in the analyzing process. Data analyzed in this paper mainly come from two criminal cases. It happens that no witness appears in court in the two cases. The analysis could be more satisfactory if we had collected data from more serious cases where more participants were involved, because data in such cases can reveal more subtlety and complexity in courtroom questioning. In this final section, we wind up our discussion by briefly pointing out directions for future research. One direction future research might take is to conduct a contrastive study of courtroom questioning between China and other countries, which can facilitate mutual understanding and offer some insight into the resolution of legal cases concerning foreign interests. We can also draw lessons from the advantages of other legal system, thus adapting our trial system to the international trend.

\section{Acknowledgement}

The author gratefully acknowledges the financial support by a research grant from Guangdong Planning Office of Philosophy and Social Science (GD12XWW01).

\section{References}

Adelsward, V., Aronsson, K., \& Linell, P. (1988). Social Identity from the Perspective of the Defendant. Semiotica, 71(3/4), 261-284.

Atkinson, M., \& Drew, P. (1979). Order in Court: The Organization of Verbal Behavior in Judicial Settings. London: Macmillan. https://doi.org/10.1007/978-1-349-04057-5

Brooks, W. D., \& Health, R. W. (1993). Speech Communication. Wm.C.Brown Communications, Inc.

Danet, B. (1978). Language and Law: An Overview of 15 Years of Research. In H. Giles, \& W. P. Robinson (Eds.), Handbook of Language and Social Psychology.

Drew, P. (1992). Contested Evidence in Courtroom Cross-examination. Talk at Work: Interaction in Institutional Setting. Cambridge University Press. 
Drew, P. (1990). Strategies in the Contest between Lawyer and Witness in Cross-examination. Language in the Judicial Process (pp. 39-64). New York: Plenum Press.

Hu, H. J. (2004). A General Review of Courtroom Discourse. Journal of Guangdong Universityof Foreign Studies, 1, 8-11.

Hu, H. J. (2008). A Pragmatic study of Courtroom Questioning Based on Adaptation Theory. Journal of South China Normal University, 5, 154-158.

Liao, M. Z. (2012). A Framework Analysis of Courtroom Discourse, Contemporary Rhetoric, 6, 83-91.

Liao, M. Z., \& Gong, J. J. (2015). A Study on Interruption of Court Speech and Gender. Contemporary Rhetoric, $1,43-45$.

Liao, M. Z. (2003). An Interactive Study on Courtroom Questions and Answers. Law Press.

Luchjenbroers, J. (1991). Discourse Dynamics in the Courtroom: some methodological points of description. La Trobe Working Papers in Linguistics, 4, 85-109.

Pan, Q. Y. (1997). Chinese Legal Language Across the Century. East China University of Science and Technology Press.

Philips, S. (1998). Ideology in the Language of Judges: How Judges Practice Law, Politics, and Courtroom Control. Oxford \& New York, Oxford University Press.

Ran, Y. P. (2008). A Study on the Interpersonal Pragmatic Function of Rhetoric Questions from the Perspective of Linguistic Adaptation. Modern Foreign Languages.

Sperber, D., \& Wilson, D. (1995). Relevance: Communication and Cognition. Blackwell publishers Ltd.

Sun, Y. H., \& Zhou, G. Y. (1997). Forensic Linguistics. China University of Political Science and Law Press.

Verschueren, J. (1995). The Pragmatic Return to Meaning: Notes on the Dynamics of Communication, Degrees of Salience, and Communicative Transparency. Journal of Linguistic Anthropology, 5, 127-156. https://doi.org/10.1525/jlin.1995.5.2.127

Verschueren, J. (1998). A Pragmatic Model for the Dynamics of Communication. Pragmatics: Critical Concepts. London: Routledge.

Verschueren, J. (1999). Understanding Pragmatics. Edward Arnold Limited.

Wang, J. (1999). A Study on Legal Language. Guangdong Education Publishing House.

Wu, W. P. (1995). Chinese Evidence versus the Institutionalized Power of English. Forensic Linguistics, 2, 154-167.

Yu, G. D. (2002). A Pragmatic Analysis of Code Switching In China: An Adaptation Approach. Shanxi People's Press.

Yuan, C. Y. (2010). The Covert Persuasive Power of the Rhetoric Questions in Lawyers' Defending Arguments. Contemporary Rhetoric.

Zhao, J. F. (2007). Speech Acts and Linguistic Strategies in Courtroom Discourse. Journal of Guangdong University of Foreign Studies, 2, 90-93.

\section{Notes}

Note 1. A Chinese criminal trial is different from its Anglo-Saxon counterpart in several respects. The main actors are the judge, the prosecutor and the defense lawyer. There is no jury, but there are three (or actually five) lay judges, who are seated at the front panel together with the professional judge (chairman of the court) and a clerk. The lay judges are elected representatives and usually have a good deal of court experience. Though they normally remain silent during the trial, they take an active part in the private deliberation of the court. It is the usual practice that in China the witness is not physically present during the trial except in some serious cases and their testimony is often read out to the court. The trials are rather informal. Paraphernalia like wigs or other symbolic garments are not used, and hearings are carried out in a rather informal way. The whole procedure is less adversarial than in the Anglo-Saxon system, and the difference between examination and cross-examination, for example concerning types of questions, is not so clear-cut. The judge is often fairly active during hearings. Trials are open to general public, although often (at least in petty cases) there are few or no auditors present.

Note 2. Transcription is the use of symbols to show sounds or sound sequences in written form. A distinction is 
made between two types of transcription. Broad transcription uses only the distinctive sounds of a language. It does not show the finer points of pronunciation. Narrow transcription uses phonetic symbols for various sounds, including symbols to show in detail how a particular sound is pronounced. It is used to show finer points of pronunciation.

\section{Copyrights}

Copyright for this article is retained by the author(s), with first publication rights granted to the journal.

This is an open-access article distributed under the terms and conditions of the Creative Commons Attribution license (http://creativecommons.org/licenses/by/4.0/). 